\title{
Contribuições da linquistica sistêmico-funcional (LSF) para o entendimento do texto literário em contexto de formação de tradutores ${ }^{1}$
}

\author{
Contributions of systemic-functional linguistics to the understanding \\ of literary texts within contexts of translators training
}

\author{
Adail Sebastião Rodrigues-Júnior \\ Universidade Federal de Ouro Preto
}

Resumo: Este capítulo parte da definição de texto como artefato (cultural) para discutir formas de abordagem do texto literário em contexto de tradução. Depreende-se dessa discussão que as relações entre o texto original e sua retextualização para uma línguaalvo, no par linguístico inglês-português, não são diretas, mas, ao contrário, saturadas de ideologias. As perguntas que orientaram a escrita deste capítulo foram: O que deve ser levado em conta no texto literário no momento de sua tradução? Como traduzi-lo de modo a apreender todas as relações que a trama faz com a realidade (ficcional) de seus personagens, em contextos sociais às vezes tão adversos, quando comparados com o contexto da cultura receptora? As discussões conduzem para o reconhecimento da problemática instaurada no ato de traduzir, sobretudo quando se utiliza o arcabouço teóricometodológico da Avaliatividade (Appraisal) para o entendimento dessa problemática.

Palavras-chave: Tradução literária. Ideologia. Avaliatividade; Formação de tradutores.

1. Texto apresentado na mesa redonda "Contribuições da LSF para o trabalho com a linguagem", durante a 2a. Jornada de (Multi)Letramentos e o II Workshop do SAL-Brasil, no dia 24 de setembro de 2012, na Universidade Federal de Santa Maria, Rio Grande do Sul. Agradeço à minha colega Sara Regina Scotta Cabral (UFSM) pela leitura da primeira versão deste texto. 
Abstract: Stemming from the concept of cultural artifact, this paper discusses how to approach the literary text in translation context. The study highlights that the relations between original and translated texts are not straightforward, but on the other hand, are grounded on ideological stances. The questions on which the study has focused its analyses are: What has to be considered in literary texts during the translation process? How the translator should translate it in order to capture all the nuances of the plot and its relations to the fictional world of the characters, often so different from the context

Adail of the receiving culture? The discussions show that the act of translating is not a clear-cut Sebastião process, especially when Appraisal theory is brought to the scene of translation to help

Rodriguesunveil hidden ideologies throughout the process of translating literature.

Júnior Keywords: Literary translation. Ideology. Appraisal. Translator training.

\section{O escopo deste capítulo}

Um dos desafios no campo das abordagens textuais da tradução aplicadas ao ensino de tradução literária é o entendimento, por parte do tradutor, sobretudo em formação, do conceito de texto como artefato, discutido por Halliday e Matthiessen (2004, p. 3-5). Quando visto como uma espécie, o texto, segundo os autores, guarda relações estruturais parecidas entre si; todavia, quando visto como artefato, um leque de possibilidades se nos abre, porque o texto, antes de ser meramente um condensado de estruturas léxico-gramaticais, revela aspectos sociais e culturais que, potencialmente, direcionaram as escolhas linguísticas de seus produtores. Isso, por si só, demonstra que textos são construtos cujos propósitos servem, entre outros, para a configuração sintagmática de escolhas sistêmicas de uma dada cultura. Com base nesse raciocínio, o que me parece, por exemplo, comum num determinado contexto de produção linguística, pode ser incomum, ou, até mesmo, inviável, em outro contexto, sobretudo se estamos falando de relações contrastivas entre culturas.

Essa ideia de relatividade linguística entre culturas é um desafio para o tradutor em formação, em especial quando trazemos para a cena da discussão o texto literário. Especificamente na narrativa em prosa, cuja constituição se sustenta num conjunto de estruturas linguísticas nem sempre apreendidas de pronto pelo leitor-tradutor, a questão de como enxergar esse tipo de gênero, de modo a relacioná-lo com aspectos culturais, com as experiências de mundo ficcional de seus personagens e os impactos dessas experiências com as representações de mundo de seus leitores, é tarefa complexa para o tradutor experiente, quiçá, para o em formação. 
Esse desafio é uma constante na sala de aula. Meus alunos mormente me questionam, assombrados: 'O que devo levar em conta no texto literário?' 'Como traduzi-lo de modo a apreender todas as relações que a trama faz com a realidade (ficcional) de seus personagens, em contextos sociais às vezes tão adversos, quando comparados com o contexto da cultura receptora?' Nesse momento, a LSF entra em cena.

Se entendermos as estórias, em seus variados formatos, como "gêneros centrais de todas as culturas", imersos na cotidianidade de nossas vidas, usadas também como forma de 'representar' o caos social, suas nuances, bem como os comportamentos dos sujeitos sociais (cf. MARTIN; ROSE, 2008, p. 49), facilmente verificamos que as narrativas em prosa - um dos vários formatos das estórias - são textos cujas especificidades linguísticas requerem uma leitura diferenciada. Isso porque a narrativa pretende-se um exemplar da cultura à qual pertence, sem, no entanto, transitar numa realidade absoluta, concreta, mas sim, ficcional, que deixa 'pistas' das intenções comunicativas de sua autoria, enviesadas pelo enredo e pelas ações de seus personagens.

Ao se deparar com a narrativa, textualizada por meio dos recursos potenciais de uma dada língua, numa dada cultura distinta da brasileira, o tradutor em formação precisa identificar nesse texto as 'pistas' que sinalizam seus propósitos comunicativos. Além da análise dos paratextos (capa, contracapa, orelha, editoria etc.), o tradutor assume, nesse momento, a postura de um leitor que, segundo Martin e White (2005), centra-se mais como um agente a expressar uma certa "subjetividade social" (p.62), i.e., leitores que se posicionam frente ao artefato-texto. Tradutores devem ser, antes de tudo, leitores, e nenhuma leitura, por mais básica que seja, está totalmente isenta de posicionamentos pessoais.

Nesse ponto, a voz do artefato-texto entra em contato com a voz do leitor-tradutor, fazendo deste um leitor ideológico que, muito antes de apenas buscar correspondências entre o texto de partida e a cultura receptora, buscará avaliar o texto-objeto de análise, identificando-se, ou não, com seus propósitos comunicativos. É nesse aspecto que teóricos da tradução preocupados com as questões culturais e ideológicas (Munday, Venuti, Tymoczco, Harvey, May, Hermans, entre outros) dizem que o tradutor é um quase-autor, porque pode manipular o texto de partida conferindo-lhe novos aspectos, outros rumos comunicativos.
Contribuições

da linguística

sistêmico-

funcional

(LSF) para o

entendimento

do texto

literário em

contexto de

formação de

tradutores 
Mas essa situação, longe de ser confortável, requer um conjunto de ferramentas que, de um lado, permitam ao tradutor retextualizar o texto e, de outro, manter-se vinculado à mensagem do original, de modo a evitar cair no campo polêmico da adaptação, da reescrita. Mas será isso possível? Será que o texto, ao ser transposto de uma cultura à outra, por si só não sofre mudanças que nos permitiriam questionar sua fundamentação, sua essência mesma, tal qual potencialmente textualiAdail zada na cultura de origem, a partir das escolhas sistêmicas à disposição Sebastião RodriguesJúnior de seu/sua autor(a)?

No contexto de formação de tradutores, esse desafio é constante. Para iniciar uma discussão nesse campo, é fundamental que o tradutor inexperiente se torne leitor e procure identificar, no artefato-texto, as pistas que mostrem o leitor-implícito (no sentido de Iser), discutidas em Munday (2008), cuja análise faz conexões muito promissoras entre a noção de leitor-implícito e os conceitos hallidayanos de contexto de cultura e de situação. É, pois, fundamental entender o texto original como um gênero, nesse caso um tipo de estória (ficcional), justaposto a aspectos experienciais representados por seus personagens [campo], em relação ideológica entre o autor-implícito (quem está por trás da ficção) e o leitor-implícito (a que tipo de leitor ideológico o autor-implícito quer chegar) [relação].

Para que isso aconteça, o tradutor em formação precisa identificar a 'voz narrativa'. Peden (2002) faz provocações nesse aspecto, ao perguntar como, de fato, iniciamos a tradução de uma narrativa literária: Que elementos linguísticos devem ser levados em conta nesse ato? Para Peden, é praticamente impossível iniciar a tarefa tradutória sem antes identificar quem está contando a estória, ou seja, quem está narrando os fatos, dando vida aos personagens e constituindo suas realidades ficcionais. Concordo com Peden e entendo, ademais, que a voz narrativa é o elemento central, mas que, sobretudo, deve ser destrinchada de modo a possibilitar ao tradutor a captura de possíveis manipulações ideológicas do artefato-texto, algumas vezes expressas por avaliações invocadas (invoked) e não inscritas (inscribed), denominadas, por Martin e White (2005, p. 61-68), como realizações indiretas (a esse respeito, ver também MARTIN, 1999; MUNDAY, 2012). A partir dessa perspectiva, o texto resultante do trabalho tradutório ganha novos contornos, porque se liberta da relação meramente estrutural, na qual se pressupõe a existência de uma equivalência absoluta entre 
original e tradução, para expandir-se e identificar na estratificação da linguagem um conjunto finito de possibilidades de retextualização, elegendo o registro e a cultura como os fundamentos das escolhas tradutórias.

\section{Dois exemplos de tradução (ideológica)}

Vejo que o sistema de avaliatividade, originária das discussões acerca da modalidade (HALLIDAY, 1994, p. 88-92), traz contribuições pontuais quando seus proponentes expandem a discussão para as realizações linguísticas de ideação, localizando-a num construto semântico não exclusivamente ligado às relações interpessoais. Embora Martin e White (2005, p. 62) nos alertem acerca da presença subjetiva na análise do léxico atitudinal invocado pelas realizações ideacionais, os autores também se posicionam ao dizerem que desconsiderar tais realizações seria perceber apenas parte da linguagem como materialização de ideologias em textos. Essas nuances implícitas, discretas, formam, por assim dizer, boa parte dos elementos textuais com os quais os tradutores precisam lidar, porque, uma leve falta de percepção dessas nuances pode colocar em risco o trabalho tradutório.

É com essa ideia em mente que pretendo discutir dois exemplos ${ }^{2}$, extraídos da obra literária controversa, The Picture of Dorian Gray, publicada em 1890 e republicada, com cortes, em 1891, tida como o palco ficcional que serviu de um dos álibis da justiça londrina, no final da era vitoriana, para levar à prisão seu autor, Oscar Wilde. Os argumentos principais dos acusadores foram que, de um lado, Wilde reconhecia-se dândi e praticante de 'atos pecaminosos' de homossexualismo, e, de outro lado, fez-se presente (nesse caso, por meio da voz narrativa) na trama do referido romance, ao apresentar, nas realizações linguísticas do texto narrativo, seus pontos de vista ideologicamente constituídos (a esse respeito, ver PURCHASE, 2006).

A tradução completa da obra foi publicada originalmente em 1919, no Rio de Janeiro, três anos antes da Semana de Arte Moderna. O tradutor, João do Rio, dândi e reconhecido como o 'Wilde carioca', tencionou trazer ao leitor brasileiro uma obra de arte, porque reconhecia no

2. Para uma maior discussão desse tema, usando os mesmos dados, ver a seguinte publicação: RODRIGUES-JÚNIOR, A. S.; BARBAra, L. Linguistic constructions of appraisal in the novel The Picture of Dorian Gray and its Brazilian translation and adaptations: an exploratory analysis. Revista Brasileira de Linguística Aplicada, v. 13, n. 1, p. 229-255, 2013.
Contribuições

da linguística

sistêmico-

funcional

(LSF) para o

entendimento

do texto

literário em

contexto de

formação de

tradutores 
romance de Wilde a materialização estética da beleza subversiva da era vitoriana. Na nota do tradutor, João do Rio aventura-se a interpretar o oeuvre do renomado escritor irlandês da seguinte forma: "De resto, tudo quanto Wilde escreveu era a história do que se iria dar. E ninguém sabe dos três personagens principais do romance - Dorian, lorde Henry e Basil - quem é Wilde. São os três decerto..." (RIO, 2009, p. 27-28). O contexto social e cultural de 1919 eram propícios a novas ideias, a ideologias Adail importadas que concorreriam para o fortalecimento de ideologias naSebastião RodriguesJúnior cionais, para as manifestações de grupos minoritários que encontravam nos artistas, poetas e escritores da época seus representantes.

As adaptações, publicadas em 1974 e 1997 e feitas, respectivamente, por Clarice Lispector e Cláudia Lopes, têm como parâmetro de configuração linguística um tipo de leitor-implícito: jovens e adolescentes. Ambas as obras foram contratadas, diferentemente da versão completa de João do Rio, por editoras cujo foco é tornar disponíveis à juventude clássicos da literatura estrangeira. Para a realização da tarefa tradutória, Lispector e Lopes recorreram a cortes, reescritas, omissões, sumarizações, de modo a reconfigurar o original, tornando-o 'palatável' ao público juvenil.

Como o foco deste capítulo centra-se na discussão da voz narrativa como realização fundamental para a identificação de elementos avaliativos na linguagem ficcional, o eixo de análise localiza-se, portanto, nos processos verbais e nas orações projetantes e projetadas, bem como em outros elementos léxico-gramaticais (expansões ou circunstâncias) que porventura circundem esse eixo da voz narrativa. Os dados, pois, foram organizados tendo essa estrutura em mente. É muito importante o destaque desse eixo, porque será nele que o tradutor em formação encontrará os elementos linguísticos que direcionarão suas decisões e, consequentemente, suas escolhas tradutórias. Para a execução dessa tarefa, o tradutor deve ter como parâmetro os possíveis impactos da obra original sobre o leitor-implícito da cultura de partida, para buscar, na cultura receptora, equivalentes que correspondam a esses impactos, embora seja sabido que mesmo em situações de reescrita e adaptação, é possível encontrar pontos de correspondência entre original e retextualizações (cf. YALLOP, 2001).

Analisemos o primeiro excerto ${ }^{3}$.

3. OW: Oscar Wilde, remetendo-se ao original (1891); JR: João do Rio, sinalizando a tradução completa (1919); e LIS e LOP: Clarice Lispector (1974) e Cláudia Lopes (1997), referindo-se, respectivamente, às adaptações. 


\begin{tabular}{|c|c|c|c|}
\hline OW & $\begin{array}{c}\text { 'I know you } \\
\text { will laugh at } \\
\text { me,' }\end{array}$ & he replied, & $\begin{array}{c}\text { 'but I really can't exhibit it. I } \\
\text { have put too much of myself } \\
\text { into it.' }\end{array}$ \\
\hline JR & $\begin{array}{c}\text { - Eu sei que } \\
\text { rirás de mim - }\end{array}$ & $\begin{array}{c}\text { replicou o } \\
\text { outro -, }\end{array}$ & $\begin{array}{c}\text { mas não posso realmente expô- } \\
\text {-lo. A essa tela comuniquei } \\
\text { muito de mim próprio. }\end{array}$ \\
\hline LIS & $\begin{array}{c}\text { - Pode rir de } \\
\text { mim - }\end{array}$ & $\begin{array}{c}\text { respondeu o } \\
\text { pintor. }\end{array}$ & $\begin{array}{c}\text { Mas não exporei o quadro. Co- } \\
\text { loquei nele muito de meu eu. }\end{array}$ \\
\hline LOP & Omitido & Omitido & Omitido \\
\hline
\end{tabular}

O eixo da voz narrativa, realizado linguisticamente pelos processos verbais replied, replicou e respondeu, e as orações projetadas, mostram que Basil Hallward, especificamente na projeção but I really can't exhibit it. I have put too much of myself into it, além de avaliar sua obra-prima (apreciação positiva do tipo valoração), expressa outro tipo de sentimento. A projeção, circunscrita no campo da avaliação invocada, porque lança mão da estrutura ideacional, revela que Basil tem problemas subjetivos com a exposição do retrato de Dorian Gray. Esse fato, questionado por seu interlocutor, lorde Henry, faz com que Basil acione recursos léxico-gramaticais pertencentes a campos semânticos da dúvida, da insegurança e, talvez, da ansiedade. A partícula but causa uma espécie de expectativa contrária à esperada (cf. MARTIN; ROSE, 2007, p. 56-57), uma vez que a exposição da obra de arte seria uma consequência natural do trabalho do pintor. Martin e Rose (ibid.) informam que partículas concessivas como but, por exemplo, indicam engajamento por parte do falante/escritor, mesmo que seja no campo do posicionamento contrário à expectativa natural do discurso produzido. Nesse caso específico, os autores esclarecem que tal atitude mostra aspectos subjetivos, mormente velados, que podem ser explicitados por meio de análise da avaliação invocada. Esse ponto demonstra que Basil não pretende expor sua obra-prima por questões subjetivas, inseridas no campo da emoção e, talvez, da afetividade, desvelando seus sentimentos pela figura do retrato, nesse caso, Dorian Gray.

As traduções, a seu turno, com exceção de LOP, que omitiu esse eixo da voz narrativa, tentaram expressar esse tipo de sensação, embora as escolhas ideacionais comuniquei e coloquei pudessem realizar melhor o conteúdo semântico do original se se localizassem no seguinte da linguística

sistêmico-

funcional

(LSF) para o

entendimento

do texto

literário em

contexto de

formação de

tradutores 
construto léxico-gramatical: dei muito de mim mesmo, do meu eu, escolha que parece indicar, com mais naturalidade (no sentido de 'colocado' [collocation]), o investimento pessoal, subjetivo, de alguém sobre algo ou outro alguém. Mesmo assim, não é tão simples essa escolha, pelo fato de o tradutor ter de lidar com um ponto de vista narrativo subjetivo, implícito, que precisa ser 'desvendado', ação que, como alertam Martin e White (2005, p. 62), não está isenta de possíveis equívocos.

Adail o próximo excerto traz desafios parecidos.

Sebastião

Rodrigues-

Excerto 2

Júnior

\begin{tabular}{|c|c|c|c|c|c|}
\hline OW & $\begin{array}{l}\text { Lord Henry } \\
\text { smiled, and, } \\
\text { leaning down, } \\
\text { plucked a pink- } \\
\text { petalled daisy } \\
\text { from the grass, } \\
\text { and examined it. }\end{array}$ & $\begin{array}{l}\text { 'I am } \\
\text { quite sure } \\
\text { I shall un- } \\
\text { derstand } \\
\text { it,' }\end{array}$ & $\begin{array}{l}\text { he } \\
\text { replied, }\end{array}$ & $\begin{array}{l}\text { gazing in- } \\
\text { tently at } \\
\text { the little } \\
\text { golden } \\
\text { white- } \\
\text { feathered } \\
\text { disk, }\end{array}$ & $\begin{array}{l}\text { 'and I can be- } \\
\text { lieve anything, } \\
\text { provided that it } \\
\text { is incredible.' }\end{array}$ \\
\hline $\mathrm{JR}$ & Omitido & $\begin{array}{l}\text { - Estou } \\
\text { bem certo } \\
\text { de que } \\
\text { compre- } \\
\text { enderei }\end{array}$ & $\begin{array}{c}\text { afirmou } \\
\text { ele, }\end{array}$ & $\begin{array}{l}\text { olhando } \\
\text { atenta- } \\
\text { mente o } \\
\text { disco- } \\
\text { zinho } \\
\text { dourado, } \\
\text { de pétalas } \\
\text { brancas. }\end{array}$ & $\begin{array}{l}\text { E, quanto a crer } \\
\text { nas coisas, eu } \\
\text { creio em todas } \\
\text { elas, desde que } \\
\text { sejam incríveis. }\end{array}$ \\
\hline LIS & Omitido & $\begin{array}{l}\text { - Estou } \\
\text { certo de } \\
\text { que o en- } \\
\text { tenderei. }\end{array}$ & Omitido & Omitido & $\begin{array}{l}\text { Quanto a acre- } \\
\text { ditar, sou capaz } \\
\text { de acreditar } \\
\text { em tudo, desde } \\
\text { que seja coisa } \\
\text { absolutamente } \\
\text { incrível. }\end{array}$ \\
\hline LOP & Omitido & Omitido & Omitido & Omitido & Omitido \\
\hline
\end{tabular}

No tocante à voz narrativa, no excerto 1 o narrador expressou seu ponto de vista por intermédio da oração projetada; no caso do excerto 2 , o ponto de vista narrativo, no momento de explicitação da feminilidade do personagem lorde Henry, localiza-se na oração Lord Henry smiled, and, leaning down, plucked a pink-petalled daisy from the grass, and examined it, iniciada com o processo comportamental smiled, seguida de outro processo comportamental na oração encaixada leaning down, de um material, plucked, e, por fim, de um comportamental, na região limítrofe de mental, examined (cf. HALLIDAY; MATTHIESSEN, 2004, p. 251). Nesse caso, Oscar 
Wilde imprimiu a lorde Henry a personificação de um dândi de comportamento efeminado, em diálogo com seu amigo Basil, artista com problemas implícitos de afetividade em relação a Dorian Gray.

Uma análise dos elementos de avaliatividade inscrita (explícita), presentes no excerto 2, apenas revelariam que a cena discursiva constrói-se sobre a avaliação do tipo apreciação, percebida pelo adjunto modal intently, intensificada pela gradação quite sure (força) e pela escolha lexical incredible (apreciação do tipo reação). No entanto, a análise se expande quando olhamos para os elementos invocados, implicitamente localizados na construção ideacional apresentada no parágrafo anterior, dentro da voz narrativa: o evento ocorre num jardim, com um dos personagens apreciando margaridas e expressando uma curiosidade insaciável acerca do assunto complexo que lorde Henry e Basil discutiam (...and I can believe anything, provided that it is incredible.). As orações não projetadas, ou seja, as que não fazem parte direta do construto semântico circunscrito aos processos verbais (Lord Henry smiled...; gazing intently at...) revelam explicitamente que o narrador esculpiu um personagem que, além de curioso, possui traços comportamentais de feminilidade que, possivelmente, serviram de argumento para que os críticos da obra afirmassem que Wilde representou a si mesmo no romance (cf. PURCHASE, 2006).

As traduções, por sua vez, amenizaram o peso semântico de feminilidade inscrito no original, sobretudo porque omitiram, inclusive a versão completa de João do Rio, a cena discursiva de lorde Henry no jardim, retextualizando parcialmente o ponto de vista narrativo responsável pela construção (no sentido de construing) ideacional desse personagem e de suas experiências de mundo (ficcional).

\section{Tradução literária e eixo narrativo: palavras finais}

No campo da tradução literária, o ponto de vista narrativo ${ }^{4}$ parece ser a estrutura fundacional para o desenvolvimento da trama, sendo, igualmente, o ponto de partida para que o tradutor retextualize o original e seus efeitos discursivos. Essa estrutura é, no entanto, muitas vezes mal interpretada por tradutores, levando-os a problemas de escolhas linguísticas. Neste texto, foram estabelecidos três elementos textuais típicos do ponto de vista narrativo, formando o eixo sobre o qual todo o enredo e as características dos personagens são construídos. Esse
Contribuições

da linguística

sistêmico-

funcional

(LSF) para o

entendimento

do texto

literário em

contexto de

formação de

tradutores

4. Para uma discussão acerca do ponto de vista narrativo em contextos monolíngues, ver Simpson (1993). 
eixo se constitui de processos verbais, ou verbos projetantes, e orações projetadas, ambos considerados como elementos principais da dialogia do texto literário; os elementos secundários são, em sua maioria, formados por circunstâncias, adjuntos modais ou expansões, que sinalizam comportamentos, opiniões, ideias e avaliações relacionadas aos personagens. Ressalte-se que ambos os elementos - principais e secundários constituem o eixo dialógico, embora sejam nos elementos secundários que

Adail o ponto de vista narrativo da obra aqui analisada aparece explicitamente.

Sebastião

A definição do eixo narrativo abre perspectivas mais claras para Rodrigueso entendimento do texto literário em contexto tradutório, servindo de Júnior base para pesquisas textuais nesse campo de investigação e, em especial, para o ensino da tradução, uma área crescente no Brasil. A identificação desse eixo possibilitou descrever que a maioria das escolhas linguísticas de feminilidade localizavam-se nos elementos secundários, partes do texto em que o narrador construía as identidades dos personagens, suas expressões efeminadas e posicionamentos típicos de dândis da era vitoriana. O sistema de avaliatividade, orientado pela LSF, abriu um campo de discussão nessa direção, estabelecendo parâmetros discursivos para a identificação do eixo narrativo e seus elementos constituidores.

De uma maneira sucinta, as considerações que podemos tecer sobre essa discussão limitam-se a:

1) o sistema de avaliatividade é um recurso linguístico-discursivo promissor para o reconhecimento de posicionamentos (ideológicos) em textos literários;

2) a avaliatividade implícita, invocada, pode expandir as análises da avaliação explícita, lançando luz sobre pontos polêmicos de escolhas linguísticas saturadas de ideologia;

3) a identificação da voz narrativa e de seus elementos constituintes parece ser o foco sobre o qual o tradutor, experiente ou em formação, deve voltar sua atenção, visto que o ponto de vista narrativo congrega boa parte da construção discursiva de um romance;

4) os dois exemplos analisados sugerem que os limites entre tradução per se e reescrita não são tão claros ou explícitos, dado o conjunto de omissões que, por exemplo, a versão completa da tradução de João do Rio apresentou (ver nota de rodapé n. 2);

5) o reconhecimento de avaliações invocadas não é uma operação direta; pelo contrário, requer uma boa quantidade de dados extralinguísticos, presentes na cultura de onde o texto, ficcional ou não, surgiu. 
Nesse aspecto, os conceitos de registro e gênero podem ser úteis para o tradutor, pois facilitam a adoção de uma abordagem top-down, que considera o texto como um artefato de uma dada cultura.

\section{Referências}

HALLIDAY, M. A. K. An introduction to Functional Grammar. $2^{\text {nd }}$. ed. London: Edward Arnold, 1994.

HALLIDAY, M. A. K.; MATTHIESSEN, C. M. I. M. An introduction to Functional Grammar. $3^{\text {rd }}$. ed. London: Edward Arnold, 2004.

MARTIN, J. R. Beyond exchange: appraisal systems in English. In: HUNSTON, S.; THOMPSON, G. (org.). Evaluation in text: authorial stance and the construction of discourse. Oxford: Oxford University Press, 1999, p. 142-175.

MARTIN, J. R.; ROSE, D. Working with discourse: meaning beyond the clause. $2^{\text {nd }}$. ed. London; New York: Continuum, 2007.

. Genre relations: mapping culture. London: Oakville, 2008.

MARTIN, J. R.; WHITE, P. R. R. The language of evaluation: appraisal in English. New York; UK: Palgrave, 2005.

MUNDAY, J. Style and ideology in translation: Latin American writing in English. London; New York: Routledge, 2008.

Evaluation in Translation: critical points of translator decision-making. London; New York: Routledge, 2012.

PEDEN, M. S. A conversation on translation with Margareth Sayers Peden. In: BALDERSTON, D.; SCHWARTZ, M. (org.). Voice-overs: translation and Latin American literature. New York: SUNY, 2002, p. 142-156.

PURCHASE, S. Key concepts in Victorian literature. New York; UK: Palgrave, 2006.
Contribuições da linguística sistêmicofuncional (LSF) para o entendimento do texto literário em contexto de formação de tradutores 
RIO, J. Nota do tradutor. In: WILDE, O. O Retrato de Dorian Gray. Trad. João do Rio. São Paulo: Hedra, 2009, p. 27-28.

RODRIGUES-JÚNIOR, A. S.; BARBARA, L. Linguistic constructions of appraisal in the novel The Picture of Dorian Gray and its Brazilian translation and adaptations: an exploratory analysis. Revista Brasileira de Linguística Aplicada, v. 13, n. 1, p. 229-255, 2013.

Adail

Sebastião

SIMPSON, P. Language, ideology, and point of view. London; New RodriguesYork: Routledge, 1993.

Júnior

WILDE, O. The picture of Dorian Gray. England; USA: Penguin, 420 2003. [originalmente publicada em 1890 e revisada em 1891]

. 0 retrato de Dorian Gray. Trad. João do Rio. São Paulo: Hedra, 2009 [originalmente traduzida em 1919]

. O retrato de Dorian Gray. Trad. Adap. Clarice Lispector. Rio de Janeiro: Ediouro, 2006. [originalmente traduzida em 1974]

O retrato de Dorian Gray. Trad. Adap. Cláudia Lopes. São Paulo: Scipione, 1997.

YALLOP, C. The construction of equivalence. In: STEINER, E.; YALLOP, C. (org.). Exploring translation and multilingual text production: beyond content. Berlin; New York: Mouton de Gruyter, 2001, p. 229-246. 